\title{
Influence of duration time of CVD process on emissive properties of carbon nanotubes films
}

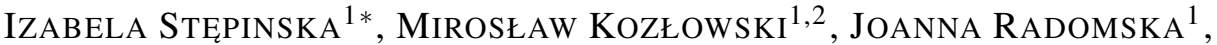 \\ HALina WronkA ${ }^{1}$, ElŻBiETA CZERWOSZ ${ }^{1}$, KAMIL SOBCZAK ${ }^{2}$ \\ ${ }^{1}$ Tele and Radio Research Institute, Ratuszowa 11, 03-450 Warsaw, Poland \\ ${ }^{2}$ Institute of Physics PASc., al. Lotników 32/46, 02-668 Warsaw, Poland
}

\begin{abstract}
In this paper various types of films made of carbon nanotubes (CNTs) are presented. These films were prepared on different substrates $\left(\mathrm{Al}_{2} \mathrm{O}_{3}\right.$, Si n-type) by the two-step method. The two-step method consists of physical vapor deposition step, followed by chemical vapor deposition step (PVD/CVD). Parameters of PVD process were the same for all initial films, while the duration times of the second step - the CVD process, were different $(15,30 \mathrm{~min}$.). Prepared films were characterized by scanning electron microscopy (SEM), transmission electron microscopy (TEM) and field emission (FE) measurements. The I-E and F-N characteristics of electron emission were discussed in terms of various forms of CNT films. The value of threshold electric field ranged from few $\mathrm{V} / \mu \mathrm{m}$ (for CNT dispersed rarely on the surface of the film deposited on $\mathrm{Si}$ ) up to $\sim 20 \mathrm{~V} / \mu \mathrm{m}$ (for $\mathrm{Al}_{2} \mathrm{O}_{3}$ substrate).
\end{abstract}

Keywords: carbon nanotubes film; field emission; SEM; TEM

(C) Wroclaw University of Technology.

\section{Introduction}

Cold cathodes based on field emission (FE) effect are used as electron emitters in electronic devices, such as lighting elements [1], X-ray tubes [2] and microwave tubes [3]. Cold electron emitters allow us to minimize the size of these devices and decrease the power consumption. Recently, research on the field emission from carbon nanotubes (CNTs) has confirmed the efficiency and stability of electron emission and a long lifetime of emission of these materials [4-7]. CNTs exhibit low threshold electrical field value that is associated with their high aspect ratio $\sim 1000$. The whisker-like shape provides the optimum geometrical field enhancement [8]. CNTs can be used as electron emitters in two different ways, as single or multiple field emitters. The first ones can be applied in electron microscopy, where a single nanotube is used as a field emitter $[9,10]$ because of its small emission area, which gives highly coherent electron beam.

*E-mail: izabela.stepinska@itr.org.pl
Multiple field emitters are made from continuous or patterned carbon nanotubes films.

The emissive properties of CNTs films were studied by many groups [8, 11-14]. An important factor affecting field emission efficiency is socalled enhancement factor $\beta$. In [11] it has been shown that the field emission behavior from CNTs could be precisely described by Fowler-Nordheim theory and also that the $\beta$ factor is the most prominent factor. This factor depends mostly on the geometric shape of the emitter (length and radius), and then on film morphology. Additionally, the chemical state of the emitter surface is also important. In [12] it was proven that a single CNT emitter has higher enhancement factor than CNTs film emitter. CNTs films of small density exhibit inferior emission properties because the density of CNTemitters and the $\beta$ factor are low. In high density films, the field enhancement factor is reduced by electrostatic screening effects, thus, the emitted current is lower. In films with medium density of CNTs, there is an ideal compromise between the CNT-emitter density and the intertube distance, 
which is sufficiently large to avoid the screening effects [13]. It is also known, that when the intertube distance is less than the height of CNTs, the $\beta$ factor decreases rapidly with decreasing the intertube distance [14]. The emission currents are very sensitive to the field enhancement factor, which rises up to 3000 or more, depending on the aspect ratio of CNTs [15].

Recently, many research groups have described the ability of application of CNTs in lighting elements. Saito with co-workers was the first who presented the prototype of a luminescent tube with cold cathode made from CNTs [16]. Bonard et al. have reported application of CNTs grown on a metallic wire in a luminescent tube [17].

In this paper we present the influence of duration time of a second step of a two-step PVD/CVD process of CNTs film preparation on emissive properties of the films. CNTs films obtained by the two-step method were studied by us earlier and their structural, topographic and morphological properties were described in other papers $[18,19]$. In this paper we also correlated the emissive properties of these films with their properties, such as topography and morphology, which were examined by scanning electron microscopy (SEM), and structural properties studied by transmission electron microscopy (TEM).

\section{Experimental}

CNTs films were obtained by the two-step PVD/CVD method. CNTs grow in CVD process by the decomposition of a xylene gas over a substrate covered with a carbonaceous film containing $\mathrm{Ni}$ nanoparticles. Initial carbonaceous-nickel (C-Ni) films were deposited by PVD method on various substrates $\left(\mathrm{Al}_{2} \mathrm{O}_{3}\right.$, Si n-type (111)). PVD process was performed from two separate sources containing fullerene $\mathrm{C}_{60}(99.95 \%)$ and nickel acetate under a dynamic vacuum of $10^{-3} \mathrm{~Pa}$. Details of preparation process were described in the paper [20]. The PVD process parameters were the same for all samples (currents of both sources $\mathrm{I}_{\mathrm{C} 60}=2.1 \mathrm{~A}, \mathrm{I}_{\mathrm{Ni}}=$ $1.1 \mathrm{~A}$, deposition time $\mathrm{t}=10 \mathrm{~min}$ and source - substrate distance $\mathrm{d}=69 \mathrm{~mm}$ ). The films obtained in
PVD process contained from $22 \mathrm{wt} . \%$ to $39 \mathrm{wt} . \%$ of Ni. In our studies, the analysis of Ni content was performed by atomic absorption spectroscopy (AAS) with a monochromatic lamp, at $232 \mathrm{~nm}$. The films were dissolved in toluene and then dried. The dry powder was used to prepare a solution based on $\mathrm{HNO}_{3}$. This solution was again dried and the resulting powder was used for AAS analysis.

During the CVD process, carbon nanotubes films grew by the decomposition of a hydrocarbon gas, which was xylene. CVD process was performed in a quartz tube in argon and xylene flow at $650{ }^{\circ} \mathrm{C}$. The duration time was 15 and 30 minutes. As a result we obtained films, which consisted of carbon nanotubes with different length, width and defects. The amount of supplied xylene was increased with the duration time of CVD process. In Table 1 we have collected the technological parameters of CVD process for investigated samples.

Table 1. Technical parameters of CVD process.

\begin{tabular}{ccccc}
\hline Type of & Sample & \multicolumn{3}{c}{ CVD } \\
\cline { 3 - 5 } substrate & no. & $\mathrm{t}[\mathrm{min}]$ & $\mathrm{T}\left[{ }^{\circ} \mathrm{C}\right]$ & xylene \\
\hline \hline \multirow{2}{*}{$\mathrm{Al}_{2} \mathrm{O}_{3}$} & $\mathrm{Sal} 1$ & 15 & 650 & $1.5 \mathrm{ml}$ \\
& $\mathrm{Sal} 2$ & 30 & 650 & $3 \mathrm{ml}$ \\
\hline \multirow{2}{*}{$\mathrm{Si}$} & $\mathrm{SSi} 1$ & 15 & 650 & $1.5 \mathrm{ml}$ \\
& $\mathrm{SSi} 2$ & 30 & 650 & $3 \mathrm{ml}$ \\
\hline
\end{tabular}

Prepared CNTs films were studied by scanning electron microscopy (SEM). SEM studies were performed with JEOL JSM-7600F field emission scanning electron microscope operating at $5 \mathrm{keV}$ incident energy, which was equipped with two detectors: secondary electrons (SE) and low angel backscattered electrons (LABE). LABE detector enabled us to define CNTs morphology by observing changes in the contrast composition. The contrast depends on the atomic number of elements in observed microstructure. Areas with higher atomic number are brighter, while those of lower atomic number are dark. The topography of the film surface was imaged using SE detector.

The field emission measurements were carried out in a dynamic vacuum $\left(10^{-5} \mathrm{~Pa}\right)$ in a diode configuration, where the cathode was our sample and anode was a metal flat surface. The measurements 
were carried out with a supply power voltage $U$ changing from 0 to $4 \mathrm{kV}$. The distance " $\mathrm{d}$ " between cathode and anode was changed from 100 to $800 \mu \mathrm{m}$. We estimated the electric field intensity $\mathrm{E}$ as $\mathrm{U} / \mathrm{d}$, assuming that this field is uniform in the emission area. The experimental setup for field emission measurements is shown schematically in Fig. 1.

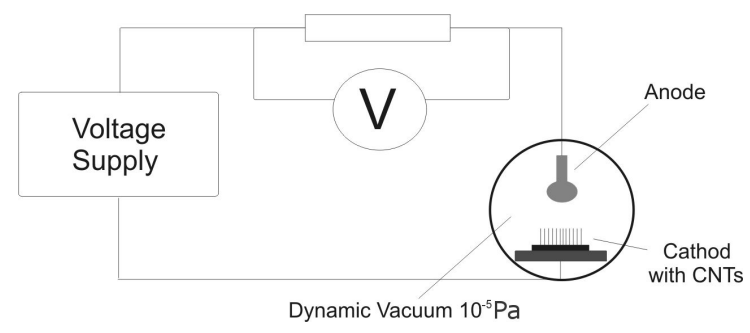

Fig. 1. Scheme of the experimental setup.

The results of field emission measurements are presented as I-E characteristics. Based on these characteristics we drew up the Fowler-Nordheim (F-N) plots, which show the mechanism of field emission phenomenon.

\section{Results and discussion}

\subsection{Substrates}

We used several kinds of substrates with a different topography and conductivity. This affected the film adhesion to the substrate as well as film topography. Depending on the substrate, the film adhesion was different - it improved when the surface of substrate had higher roughness.

SEM images of all substrates are presented in Fig. 2a, 2b. The n-type silicon (111) wafers are flat and very smooth. The $\mathrm{Al}_{2} \mathrm{O}_{3}$ ceramic substrate is composed of large grains and has higher roughness.

In Fig. 3, topographies of the films obtained in PVD process are presented. In PVD process films with thickness 200 to $300 \mathrm{~nm}$ were obtained. The samples on alundum are rough and craggy. The films on $\mathrm{Si}$ substrates are characterized by low roughness and their surface is quite smooth and does not have any irregularities. The observed carbon grains are bigger for $\mathrm{Al}_{2} \mathrm{O}_{3}$ substrate (Sall,
Sal2) than for $\mathrm{Si}$ (SSi1, SSi2), where the grains are closely packed or melted.

TEM studies have shown that all these films are composed of carbonaceous grains. TEM image of a typical fragment of a PVD film is shown in Fig. 4. We observe small Ni nanoparticles, which are dark objects regularly embedded in the matrix. Additionally, the histogram of Ni size is included. The particles have diameters from 2 to $8 \mathrm{~nm}$. Majority of the Ni nanoparticles have diameter in a range of 4 to $5 \mathrm{~nm}$.

\subsection{Carbon nanotubes films on $\mathrm{Al}_{2} \mathrm{O}_{3}$ substrate}

In Fig. 5a, 5d SEM images of samples Sal1 and Sal2 are presented. Both samples were prepared on $\mathrm{Al}_{2} \mathrm{O}_{3}$ plates. Sample Sall was obtained with CVD duration time $15 \mathrm{~min}$ and $\mathrm{Sal}-30 \mathrm{~min}$. The longer duration time resulted in increasing density and sizes of CNTs (with the length from 100 to $1000 \mathrm{~nm}$ and diameter 20 to $40 \mathrm{~nm}$ ). For sample Sal1 it is characteristic that we have found only very long CNTs $(\sim 800 \mathrm{~nm})$ and very short CNTs (100 nm in length). There is only one long CNT in the observation area of the image presented in Fig. 5a, while there are many of short CNTs in this observation area. In sample Sal2 the CNTs are longer than in sample Sal1 (up to $1 \mu \mathrm{m}$ ).

In both samples (Fig. 5a, 5d) we can observe Ni nanoparticles surrounded by carbon shells. This could be observed by comparing SEM images formed by secondary and backscattered electrons (Fig. 5b, 5c for Sal1 and Fig. 5e, 5f for Sal2). The bright spherical objects are $\mathrm{Ni}$ nanoparticles and the darker background is carbon. The Ni nanoparticles are more densely distributed on the Sal2 film surface, which is connected with the longer stay at high temperature. Also the carbonaceous matrixes differ for both the samples due to the longer duration time of the process and keeping the sample at the temperature of $650{ }^{\circ} \mathrm{C}$ for a longer time. This caused a transformation of the big carbonaceous grains into amorphous form. The sample Sal2 is more homogenous and compact than Sal1.

Field emission characteristics (I-E plots in Fig. 6) were investigated for all samples. 
a)

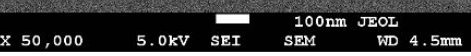

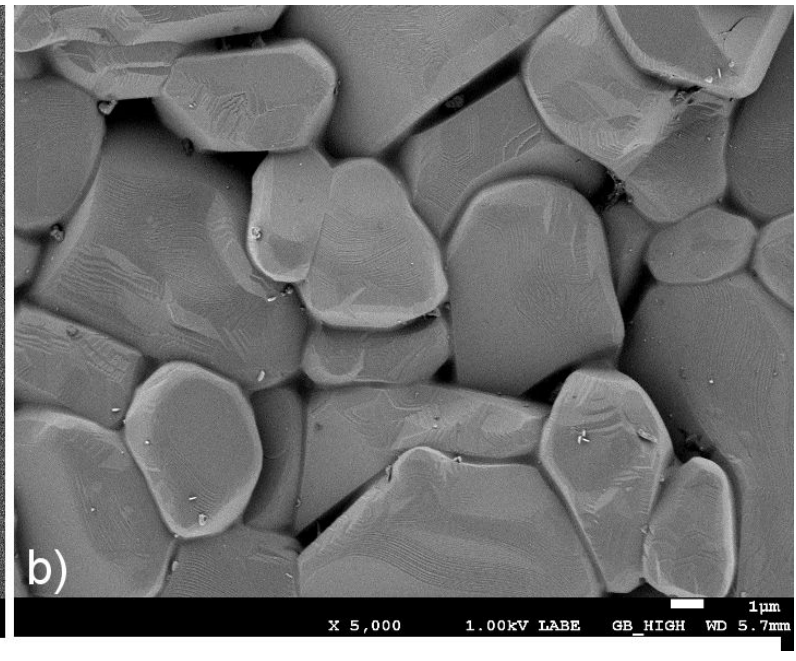

Fig. 2. SEM images of substrates: (a) $\mathrm{Si}$, (b) $\mathrm{Al}_{2} \mathrm{O}_{3}$.
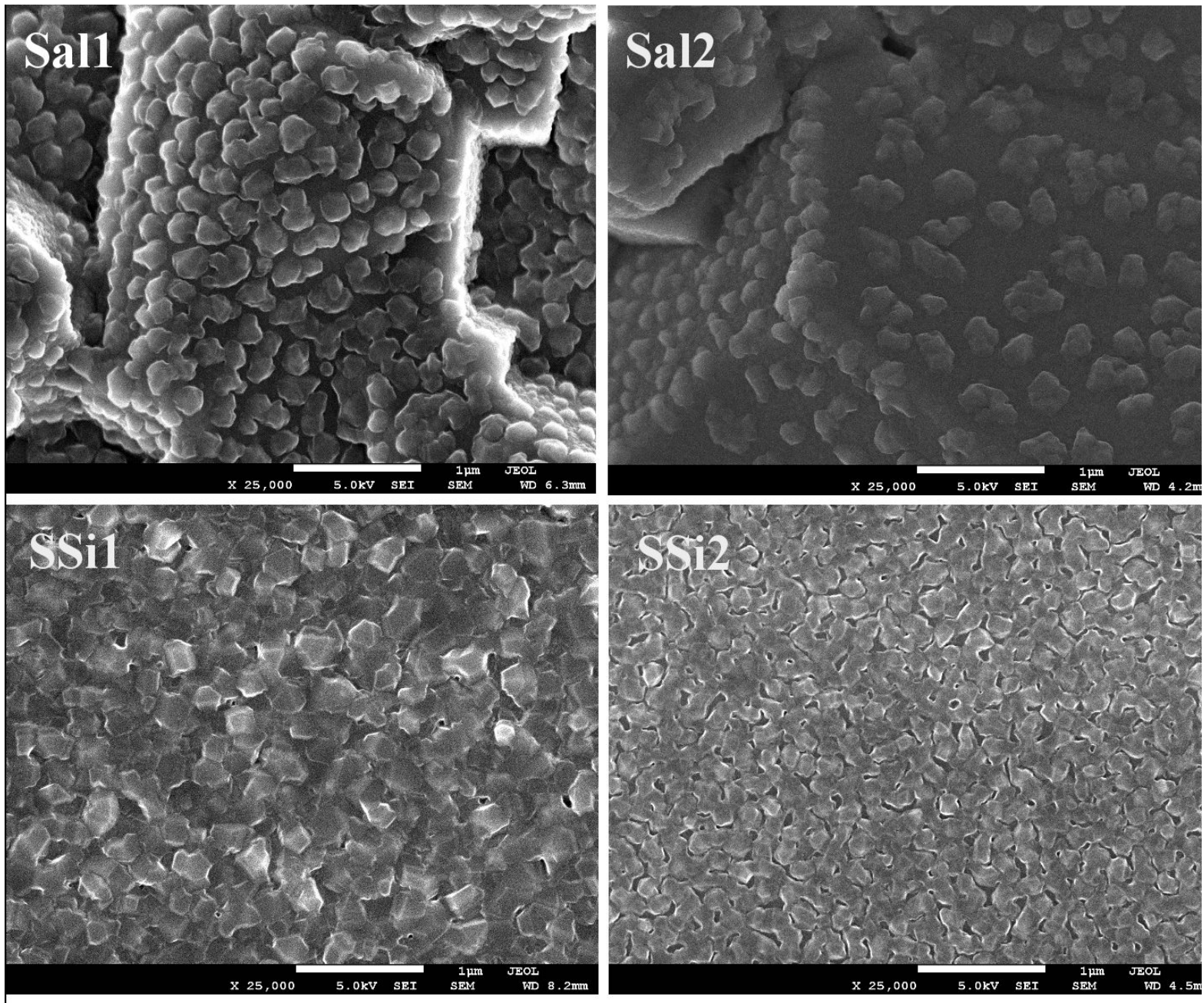

Fig. 3. SEM images of samples after PVD process. 

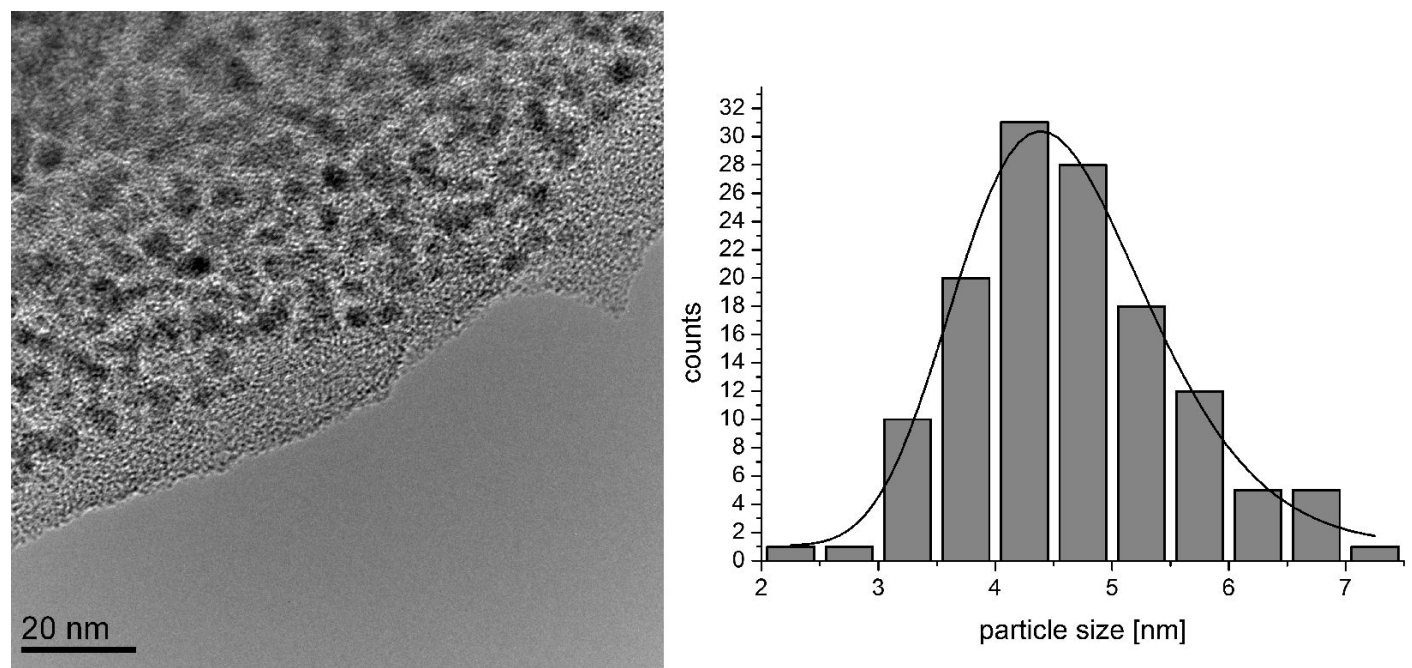

Fig. 4. TEM image of PVD film with a histogram of Ni nanoparticles size.

The threshold field values are: $\mathrm{E}_{\mathrm{thr}}=17.4 \mathrm{~V} / \mu \mathrm{m}$ for Sal1 and $E_{\text {thr }}=10.5 \mathrm{~V} / \mu \mathrm{m}$ for Sal2. The threshold electric field represents an electric field, at which currents exceed $0.001 \mathrm{~mA}$. The intensity of electron current for sample Sal1 is $\mathrm{I}=0.001 \mathrm{~mA}$ and for Sal2 I $=0.024 \mathrm{~mA}$ (for $\mathrm{E} \sim 20 \mathrm{~V} / \mu \mathrm{m}$ ). The corresponding F-N plots (Fig. 6c, 6d) show that the emission observed for sample Sal2 is pure field emission (linear characteristics in Fig. 6d). In the F-N plot for sample Sal1 we observe two regions with different slopes. This could be connected with changes of emissive centers responsible for this emission at increasing electric field value. Such effects were described in paper [21], where it was confirmed that the curvature of CNTs and their length have an influence on the field emission phenomenon due to changing the field enhancement factor $\beta$.

\subsection{Carbon nanotubes on Si substrate}

CNTs films prepared on Si n-type (111) wafers are similar to the samples on $\mathrm{Al}_{2} \mathrm{O}_{3}$. The sample SSi1 (Fig. 7a) contains rarely distributed CNTs and numerous Ni nanoparticles surrounded with carbon shells, what is seen when comparing the images of a sample obtained in SE and LABE mode (Fig. 7b, $7 \mathrm{c})$. Because of higher atomic number, Ni nanoparticles are marked as bright areas. We observed $\mathrm{Ni}$ nanoparticles on the surface of the film including carbon shells. In Fig. $7 \mathrm{~b}$ it is visible that a lot of $\mathrm{Ni}$ as irregular circle forms are hidden under the carbonaceous matrix. $\mathrm{Ni}$ is also located at various sites of CNTs especially at the ends of tubes and along their cores. On the tops of CNTs there are the oval shaped particles with diameters from few to $50 \mathrm{~nm}$. Along CNTs, some of Ni nanoparticles are more elongated and other are fragmented. It is related to the mechanism of CNTs growth, which indicates to the 'tip' growth character in the twostep method. The tip-growth mechanism was described in paper [22], where it was found that this type of growth is mostly present in CVD synthesis of carbon nanotubes. The carbonaceous matrix of these samples has a porous character. The sample SSi2 differs from the sample SSi1. In Fig. 7d,7e, 7f SEM images of this sample are presented. There is more CNTs in the observation area $\left(2.25 \mu \mathrm{m}^{2}\right)$ than for the sample SSi1. These CNTs have the lengths from $250 \mathrm{~nm}$ to $1 \mu \mathrm{m}$ and diameters between 20 and $70 \mathrm{~nm}$. The carbonaceous matrix is homogenous and we also found a lot of Ni particles surrounded by carbon (Fig. 7e, 7f).

Fig. 8 presents TEM images of the CNTs obtained in the two-step method. The picture on the left shows several nanotubes on the CNTs film surface. It is clearly visible that on the top of the tubes and along their cores the catalysts particles are present. On the right of TEM image there is 


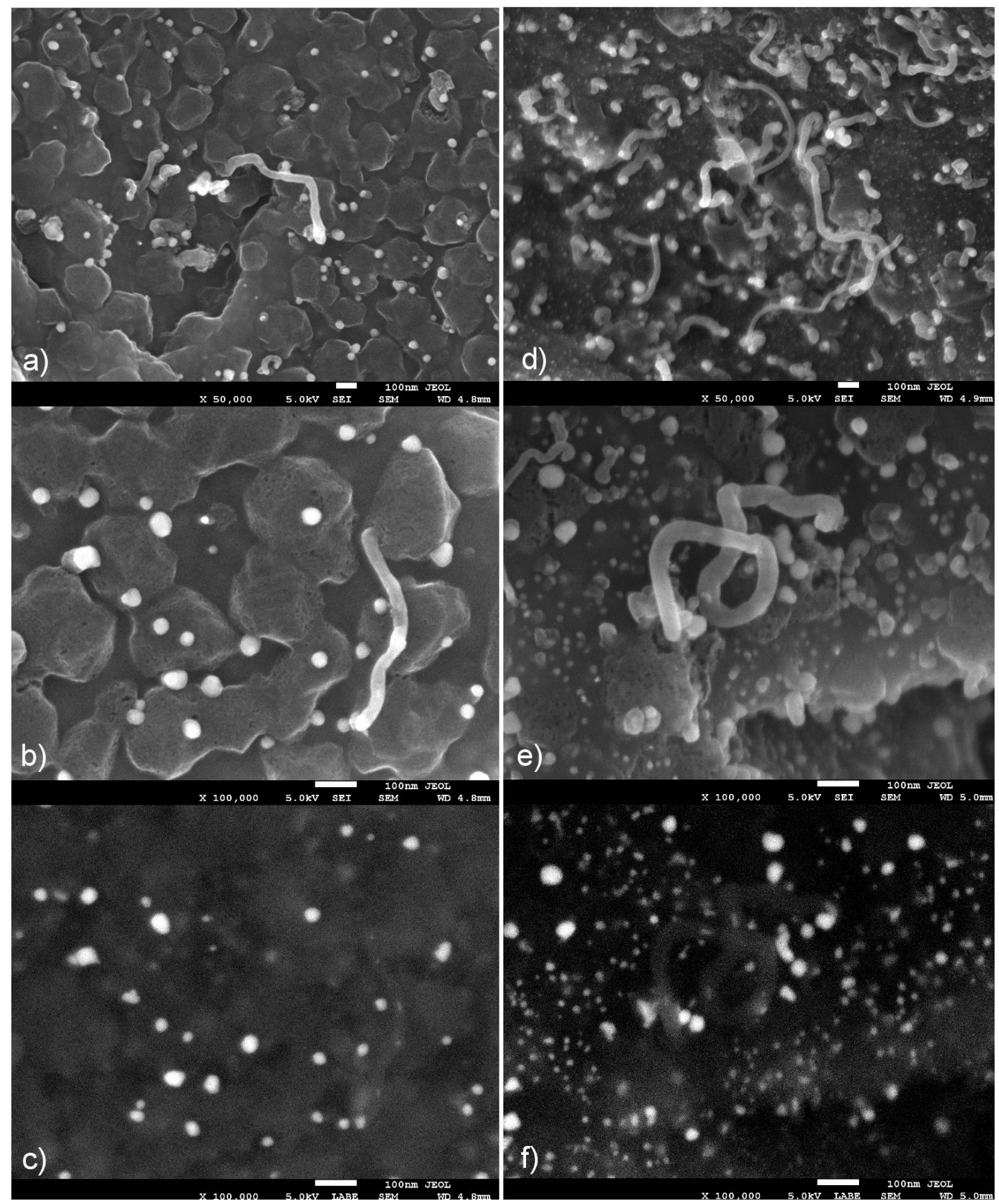

Fig. 5. SEM images of sample Sal1: (a), (b) SE mode, (c) LABE mode and of sample Sal2: (d), (e) SE mode, (f) LABE mode. 

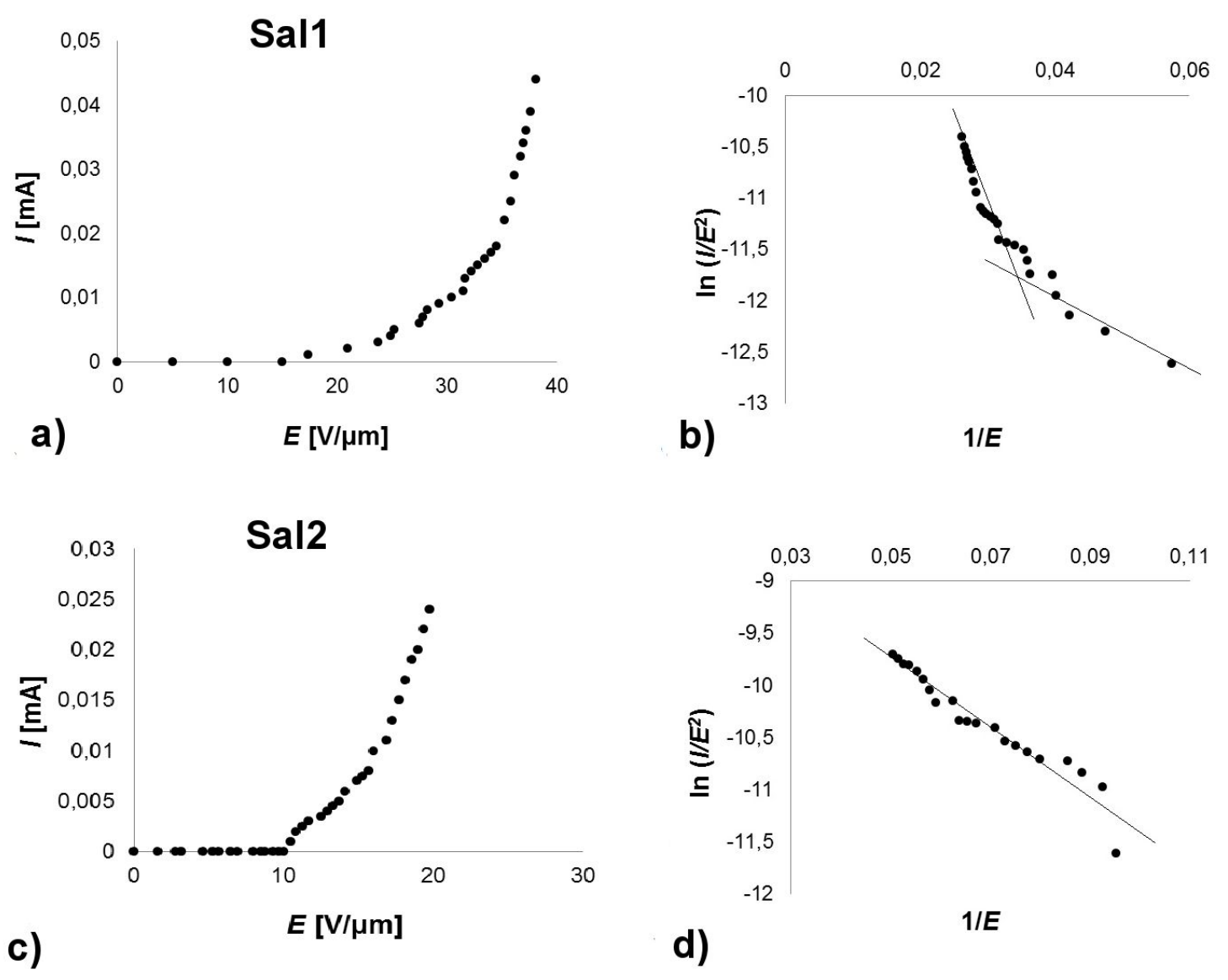

Fig. 6. I-E characteristics (a) Sal1, (b) Sal2 and F-N plots (c) Sal1, (d) Sal2.

a selected area in a high magnification, which represents an individual CNT. We observe the objects made up of a dozen graphite planes that are hollow inside.

The field emission I-E and F-N characteristics for samples SSi1 and SSi2 are shown in Fig. 9a9d. The current of electron emission for the film SSil is much higher than the currents registered for other samples at the same value of electric field. The values of threshold electric field, for samples $\mathrm{SSi} 1$ and $\mathrm{SSi} 2$ are equal to $\mathrm{E}_{\mathrm{thr}}=4.3 \mathrm{~V} / \mu \mathrm{m}$ and $\mathrm{E}_{\mathrm{thr}}=10 \mathrm{~V} / \mu \mathrm{m}$, respectively. The maximum current emission intensity is $\mathrm{I}=0.22 \mathrm{~mA}$ at the electric field of $7.6 \mathrm{~V} / \mu \mathrm{m}$ (at the supply voltage $\mathrm{U}=$ $3.8 \mathrm{kV}$ and the distance between anode and cathode of $450 \mu \mathrm{m}$ ) for sample SSi1. The current for sample SSi2 for such field is not observed because the threshold electric field $\mathrm{E}_{\mathrm{thr}}=10 \mathrm{~V} / \mu \mathrm{m}$. The
F-N plots confirm cold emission character for these samples.

From our experiment we can determine the dependence between the geometric parameters as well as the distribution of CNTs on the film surface and emissive properties of these films. In Table 2 we have collected all above mentioned parameters. The influence of CVD duration time on CNTs sizes and distribution is clearly visible. The length of CNTs increases with increasing time. Also the density of CNTs grows with increasing time. The films prepared in the short duration time of CVD process (15 min) exhibit higher field emission than the films prepared in 30 min CVD process, whereby the best emissive properties has the film obtained on Si substrate. This results from very rare distribution of CNTs. Many research groups confirmed that the sparse CNTs are better emitters than 


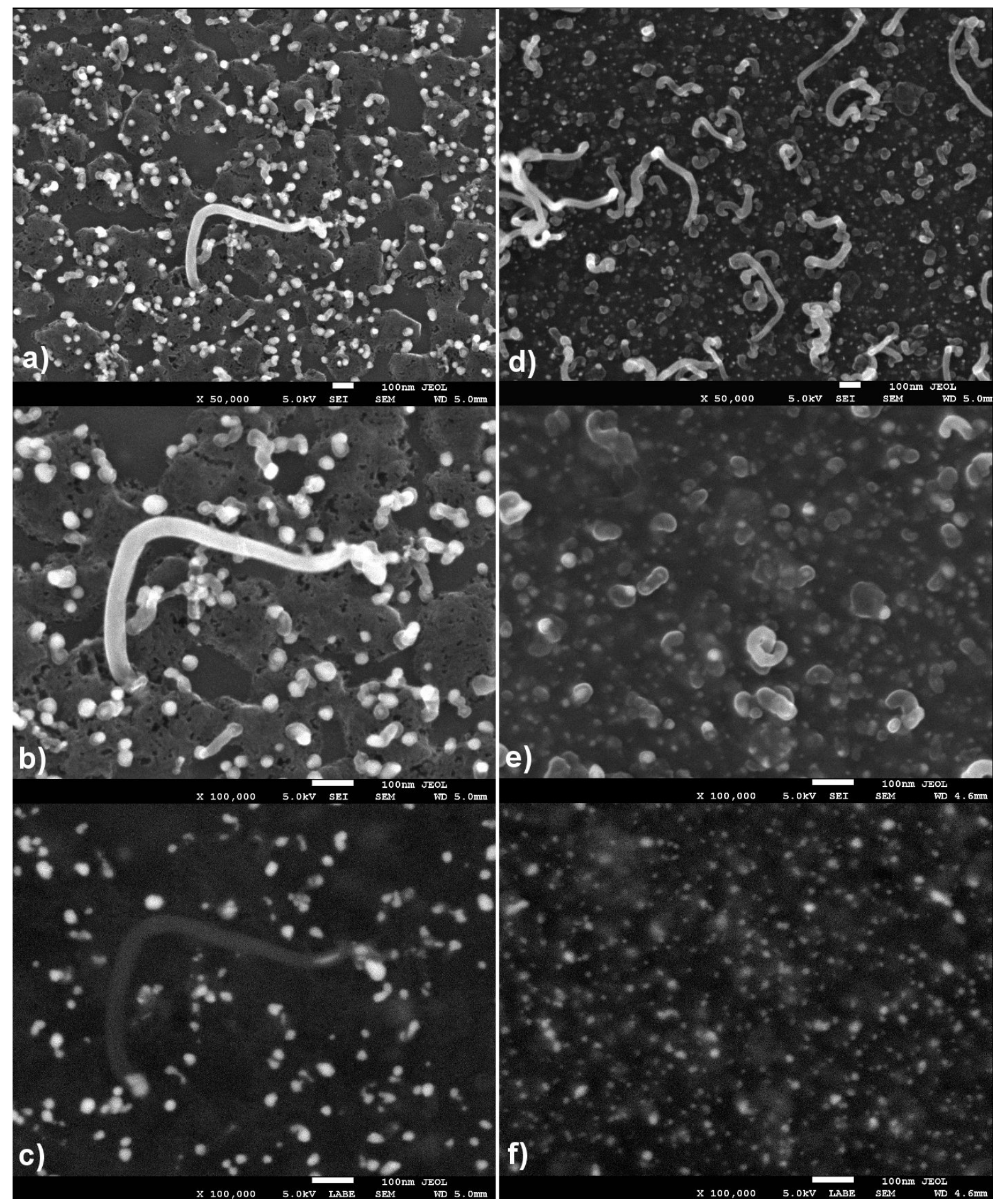

Fig. 7. SEM images of sample SSi1: (a), (b) SE mode, (c) LABE mode and of sample SSi2: (d), (e) SE mode, (f) LABE mode. 


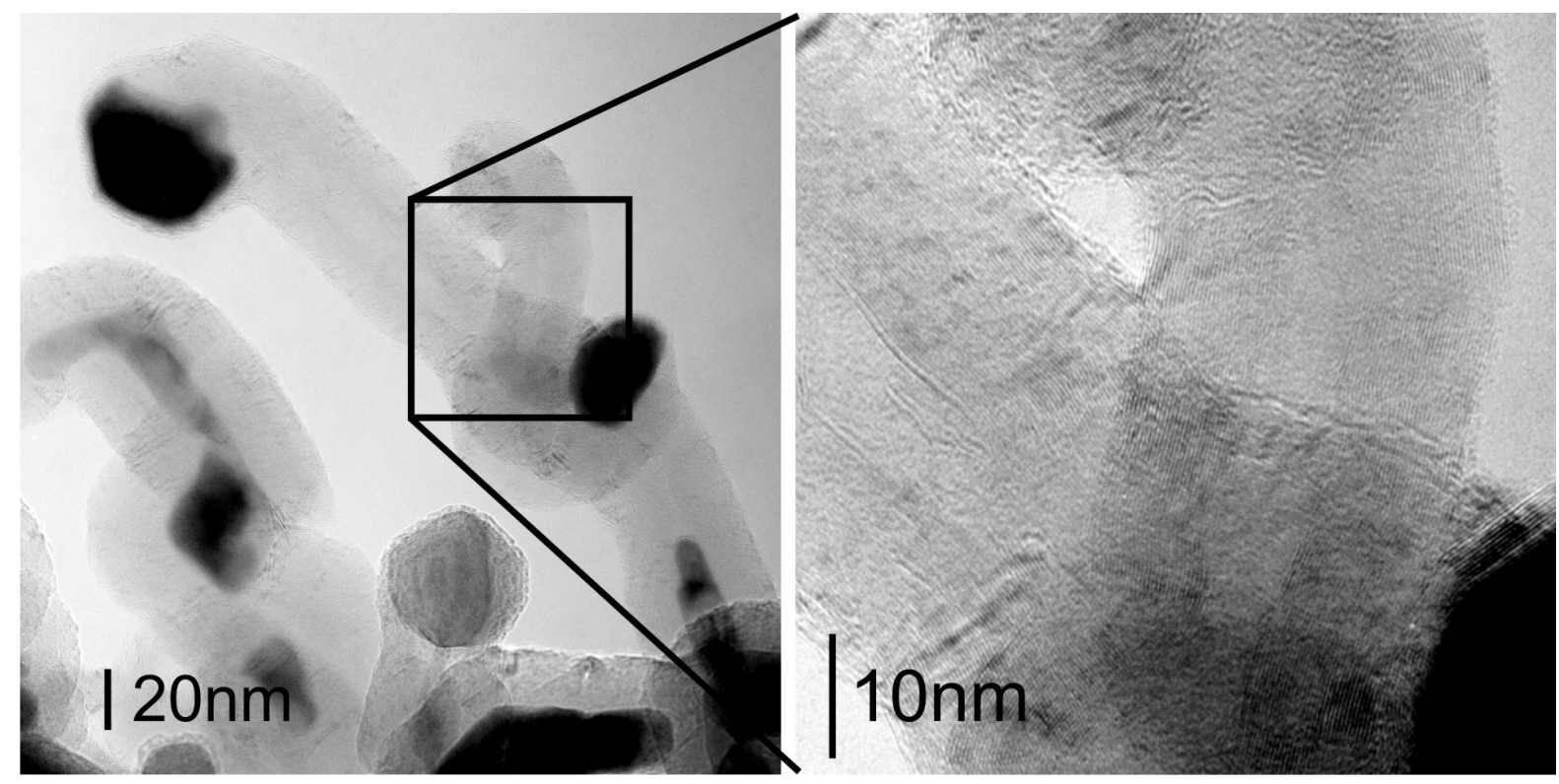

Fig. 8. TEM images of CNTs obtained in two-step method.
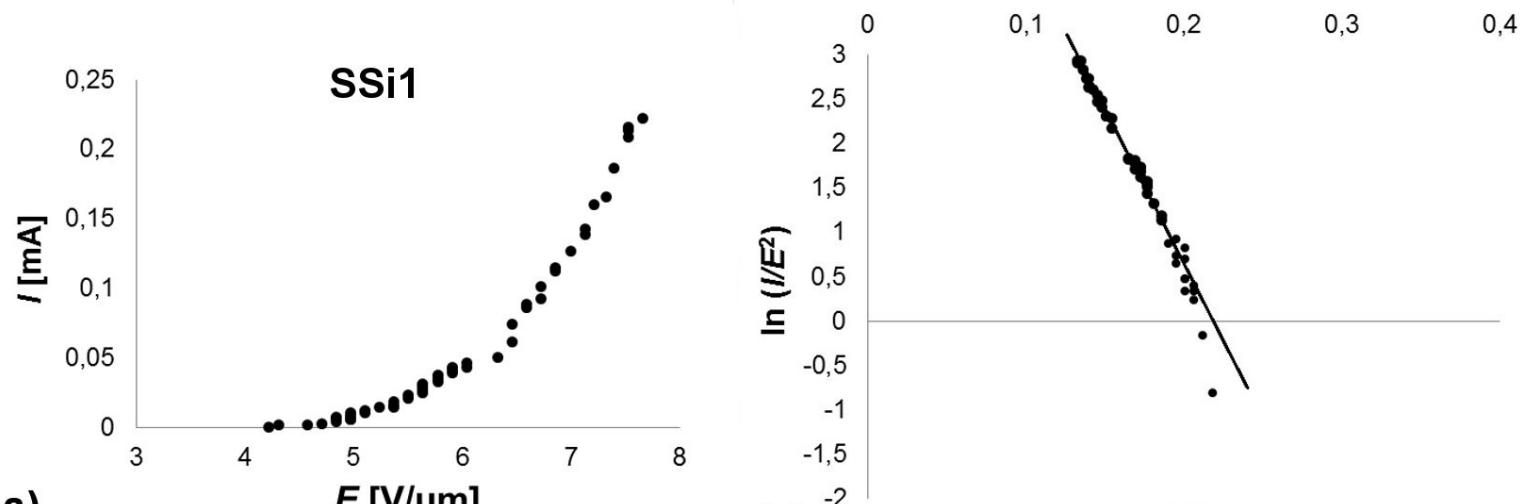

a)

$E[\mathrm{~V} / \mu \mathrm{m}]$

b)
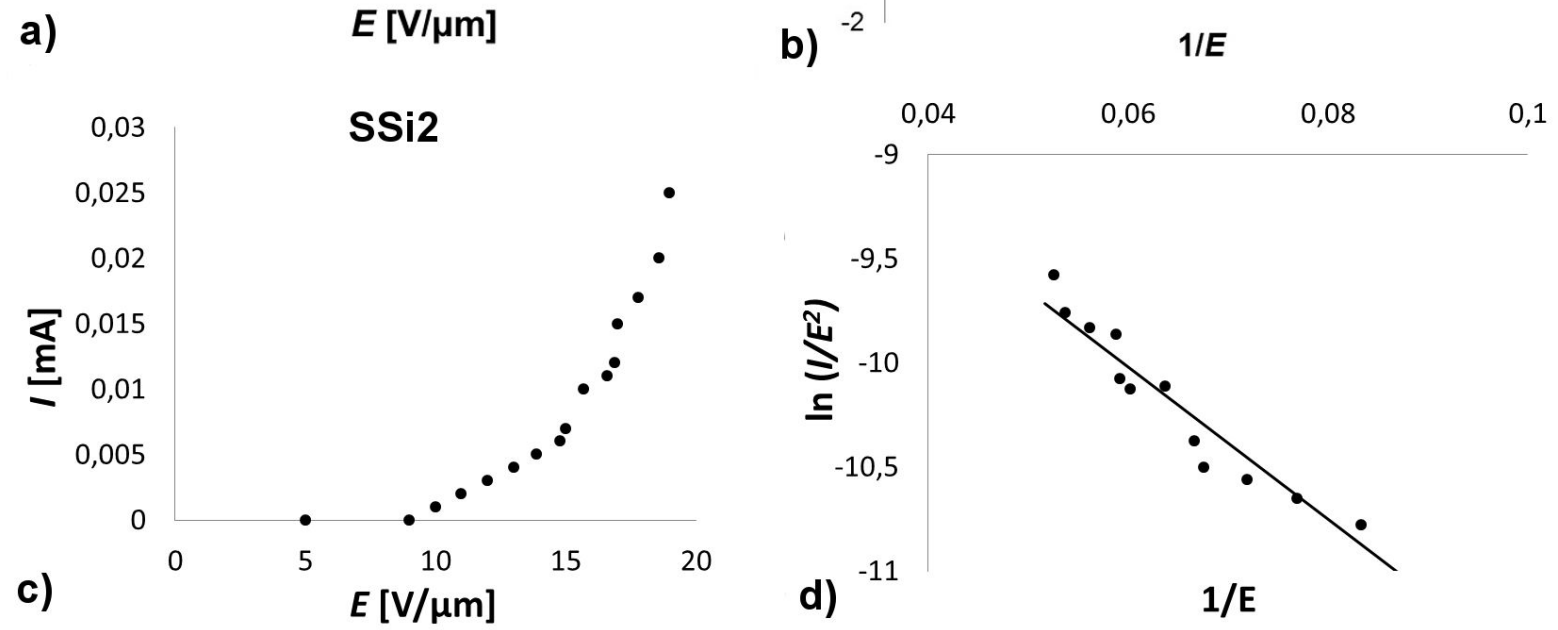

Fig. 9. I-E characteristics (a) SSi1, (b) SSi2 and F-N plots (c) SSi1, (d) SSi2. 
Table 2. Geometrical parameters, number of carbon nanotubes observed in an area of $2.25 \mu \mathrm{m}^{2}$.

\begin{tabular}{|c|c|c|c|c|c|c|}
\hline \multirow{2}{*}{ Sample } & \multirow{2}{*}{$\begin{array}{c}\text { CNTs length } \\
{[\mathrm{nm}]}\end{array}$} & \multirow{2}{*}{$\begin{array}{c}\text { CNTs diameter } \\
{[\mathrm{nm}]}\end{array}$} & \multicolumn{2}{|c|}{ No. of CNTs observed in area } & \multirow{2}{*}{$\begin{array}{c}\mathbf{E}_{\mathbf{t h r}} \\
{[\mathrm{V} / \mu \mathrm{m}]}\end{array}$} & \multirow{2}{*}{ CVD time } \\
\hline & & & Short CNTs & Long CNTs & & \\
\hline $\mathrm{Sall} / \mathrm{Al}_{2} \mathrm{O}_{3}$ & $100-800$ & $20-40$ & 5 & 1 & 17.4 & 15 \\
\hline $\mathrm{Sal} 2 / \mathrm{Al}_{2} \mathrm{O}_{3}$ & $200-1000$ & $20-80$ & 15 & 22 & 10.5 & 30 \\
\hline $\mathrm{SSi} 1 / \mathrm{Si}$ & $100-700$ & $20-50$ & 25 & 1 & 4.3 & 15 \\
\hline $\mathrm{SSi} 2 / \mathrm{Si}$ & $250-1000$ & $20-70$ & 9 & 25 & 10 & 30 \\
\hline
\end{tabular}

these densely packed. In [23] it was found that the optimal distance between individual CNTs should be $2 \mathrm{~h}$, where $\mathrm{h}$ is the length of CNT.

The F-N characteristics for an ideal field emitter are linear. In the plots presented in Fig. 7 and 8 these characteristics deviate from a straight line what is connected with the low electric fields, where mechanisms other than the field emission can dominate.

Analyzing the data in Table 2 we can conclude that some of the observed dependences (CNTs sizes and distribution density) on CVD process duration time are of the same character for all substrates. The threshold electric field depends inversely on duration time. This effect is connected with the conductive and non-conductive character of the substrate as well as with the distribution density of CNTs on the substrate. In case when there are many long CNTs on a non-conductive substrate, the emission could start at low threshold field because of high enhancement factor, and in spite of difficulties with electric current flow through the substrate (the electric current flows mainly through the film). For short and rarely distributed CNTs we need much higher electric field to start emission.

\section{Conclusions}

Reassuming, we have found that:

- Duration time of CVD process affects the CNTs distribution density on a film surface as well as the CNTs sizes.

- The distribution density and sizes of CNTs increase with an increase in duration time of CVD process due to increased amount of xylene.

- Field emission was registered for all the films, but for those with CNTs rarely distributed on the film surface, the emission was the highest.

- The threshold electric field for the films obtained on Si wafers increased with increasing duration time, while for the films on $\mathrm{Al}_{2} \mathrm{O}_{3}$ the dependence was opposite.

- The film prepared on Si substrate in CVD process in a short duration time exhibited the best emissive properties (low threshold electric field $\mathrm{E}_{t h r}=4.3 \mathrm{~V} / \mu \mathrm{m}$ and emission current $\mathrm{I}=0.22 \mathrm{~mA}$ at electric field of $7.6 \mathrm{~V} / \mu \mathrm{m})$.

Additionally, we found that the films obtained on an insulating, rough substrate had better adhesion to this substrate but parameters of the field emission were worse than for those prepared on a conducting, flat substrate ( $\mathrm{Si}$ ). Generally, we can conclude that some of observed dependences (CNTs sizes and number of distribution density) on CVD process duration time are the same for all substrates, while the threshold electric field depends inversely on duration time. This last effect is connected with the conductive and non-conductive character of the substrate as well as with the distribution density of CNTs on the substrate.

\section{Acknowledgements}

This work was supported by founds of The National Centre for Research and Development (PBS1/A5/16/2012).

\section{References}

[1] Chen J., Zhou X., Deng S.Z., Xu N.S., Ultramicroscopy, 95 (2003), 153. 
[2] Yue G.Z., QIU Q., GaO B., Cheng Y., Zhang J., Shimoda H., Chang S., Lu J.P., Zhou O., Appl. Phys. Lett., 81 (2) (2002), 355.

[3] Sarrazin P., Blake D., Delzeit L., Meyyappan M., Boyer B., Snyder S., Espinosa B., Adv. X-Ray Anal., 47 (2004), 232.

[4] ReAd M.E., Schwarz W.G., Kremer M.J., Lennhoff J.D., Carnahan D.L., Kempa K., Ren Z.F., PAC 2001 Proc., (2001), 1026.

[5] Silan J.L., Niemann D.L., Ribaya B.P., Rahman M., Meyyappan M., NGuyen C.V., Solid-State Electron., 54 (2010), 1543.

[6] OK-Joo L., Kun-Hong L., Appl. Phys. Lett., 82 (2003), 3770.

[7] Jonge N., Bonard J.M., Philos. T. R. Soc. A, 362, (2004), 2239.

[8] Filip V., Nicolaescu D., Tanemura M., OKUYAMA F., Ultramicroscopy, 89 (2001), 39.

[9] Jonge N., DRUTEN N.J., Ultramicroscopy, 95 (2003), 85.

[10] Nakahara H., Kusano Y., Kono T., Saito Y., Appl. Surf. Sci., 256 (2009), 1214.

[11] Groning P., Ruffieux P., Schlapbach L., GronING O., Adv. Eng. Mater., 5 (2003), 541.

[12] Bonard J.-M., Croci M., Arfaoui I., Noury O., Sarangi D., Chatelain A., Diam. Relat. Mater., 11 (2002), 763.

[13] Nilsson L., Groening O., Emmenegger C., Kuettel O., Schaller E., Schlapbach L., Kind H., Bonard J-M., Kern K., Appl. Phys. Lett., 76 (15) (2000), 2071.
[14] Wanga X.Q., Wanga M., Lib Z.H., XuA Y.B., HE P.M., Ultramicroscopy, 102 (2005), 181.

[15] Pogorelov E.G., Chang Y.C., Zhbanov A.I., Yong-Gu L., J. Appl. Phys., 108 (2010), 044502.

[16] Saito Y., Uemura S., Carbon, 38 (2000), 169.

[17] Bonard J.M., Stockli T., Noury O., Chatelain A., Appl. Phys. Lett., 78 (2001), 2775.

[18] KozŁowski M., DŁużewski P., Kowalska E., Czerwosz E., Cent. Eur. J. Phys., 9 (2) (2011), 344.

[19] Kowalska E., KowalczyK P., Radomska J., Czerwosz E., Wronka H., Bystrzejewski M., J. Therm. Anal. Calorim., 86 (2006), 115.

[20] Czerwosz E., DŁużewski P., Nowakowski R., Wronka H., Vacuum, 48 (1997), 357.

[21] Kowalska E., Czerwosz E., DŁużewski P.A., KozŁowski M., Radomska J., Diam. Relat. Mater, 13 (2004), 1008.

[22] Sinnott S.B., Andrews R., Qian D., RaO A.M., Mao Z., Dickey E.C., Derbyshire F., Chem. Phys. Lett., 315 (1999), 25.

[23] De Jonge N., Bonard J.-M., Philos. T. R. Soc. A, 362 (2004), 2239. 